\title{
Resistência de genótipos de videira à ferrugem
}

\author{
Francislene Angelotti(1), Claudia Regina Scapin ${ }^{(2)}$, Dauri José Tessmann ${ }^{(2)}$, João Batista Vida(2), \\ Rafael Augusto Vieira(2) e Eliezer Rodrigues de Souto(2)
}

\begin{abstract}
(1)Embrapa Semi-Árido, BR 428, Km 152, CEP 56302-970 Petrolina, PE. E-mail: fran.angelotti@cpatsa.embrapa.br (2)Universidade Estadual de Maringá, Departamento de Agronomia, CEP 87020-900 Maringá, PR. E-mail: djtessmann@uem.br, jbvida@uem.br, rfavieira@msn.com, claudiascapin@hotmail.com, ersouto@uem.br
\end{abstract}

Resumo - O objetivo deste trabalho foi avaliar a resistência à ferrugem causada pelo fungo Phakopsora euvitis, em genótipos de videira, e a eficiência da infecção de acordo com a idade das folhas e concentração de inóculo. A avaliação foi feita em 15 genótipos, com base nos seguintes componentes de resistência: número de pústulas (urédios) por $\mathrm{cm}^{2}$; tamanho das pústulas; número de esporos produzidos por pústula; e período latente. Os componentes de resistência, com exceção do período latente, apresentaram grande variação quantitativa. A análise multivariada desses componentes diferenciou cinco grupos de genótipos. Os genótipos mais resistentes foram as cultivares porta-enxertos IAC313, IAC572 e IAC766, em que a eficiência da infecção foi baixa, com pústulas menores e menor produção de urediniósporos, além de reação de hipersensibilidade no tecido em torno das pústulas. O grau de infecção aumenta com o aumento na concentração do inóculo. A ferrugem coloniza, indiscriminadamente, folhas jovens e folhas maduras de videira.

Termos para indexação: Phakopsora euvitis, Vitis, análise multivariada, reação de hipersensibilidade, resistência genética.

\section{Genetic resistance of grape genotypes to rust}

Abstract - The objective of this work was to evaluate the genetic resistance of grape genotypes to rust, caused by the fungus Phakopsora euvitis, and the infection efficiency in relation to leaf age and inoculum concentration. The evaluation was carried out on 15 genotypes, based on the following resistance components: number of pustules (uredia) per $\mathrm{cm}^{2}$, size of pustules; number of urediniospores produced per pustules; and latent period. The resistance components, except for the latent period, presented considerable quantitative variation. The multivariate analysis of resistance components discriminated five groups of genotypes. The more resistant genotypes were the rootstocks cultivars IAC313, IAC572, and IAC766, in which the infection efficiency was low, with small pustule sizes, and less urediniospores production, besides hypersensivity response on tissue surrounding the pustules. The infection increases with increasing of inoculum concentration. The rust colonizes young and mature grape leaves.

Index terms: Phakopsora euvitis, Vitis, multivariate analysis, hypersensivity response, genetic resistance.

\section{Introdução}

A ferrugem-da-videira, causada pelo fungo Phakopsora euvitis Ono, foi constatada no Brasil em 2001, no Norte do Paraná (Tessmann et al., 2004), e tornou-se endêmica nesta e em outras regiões vitivinícolas no Sul, Sudeste, Centro-Oeste e Nordeste do Brasil (Tessmann \& Vida, 2005). A doença ocorre em regiões tropicais e temperadas da Ásia, da Índia ao Japão, inclusive China, Taiwan, Coréia do Norte e Coréia do Sul. Sua constatação no Norte da Austrália foi recente (Weinert et al., 2003). No continente americano, a doença ocorre também no Sul dos Estados Unidos, América Central, Venezuela e Colômbia (Leu,
1988; Ono, 2000). Não há relato de sua ocorrência na Europa e África.

Os sintomas típicos da ferrugem são pústulas uredínicas, amarelas e pequenas, formadas predominantemente na face inferior de folhas. As pústulas coalescem e podem cobrir grande extensão do limbo foliar. A doença causa desfolha antecipada das plantas, e prejudica a maturação de frutos e ramos (Leu, 1988). Seu ciclo completo é conhecido apenas na Ásia, onde ocorre a hospedeira alternante, Meliosma myriantha (Ono, 2000). No Brasil, constataram-se apenas as fases uredinial e telial, e se pressupõe que os urediniósporos constituem o inóculo primário e secundário da doença (Tessmann \& Vida, 2005). 
As informações sobre resistência genética à ferrugem-da-videira são limitadas. Possivelmente, porque a doença não ocorre nas regiões vitivinícolas tradicionais do mundo. No entanto, a importância econômica da doença pode aumentar, em razão da expansão da viticultura nas regiões tropicais.

Cultivares originadas de Vitis labrusca, $V$. vinifera e $V$. aestivalis, e de outras espécies originadas em regiões de clima temperado, são susceptíveis à ferrugem, enquanto cultivares originadas em regiões tropicais, como: $V$. tiliifolia, $V$. simpsonii e $V$. coriaceae, são resistentes. No Brasil, tem-se verificado, em condições de campo, que cultivares originadas de V. labrusca, $V$. vinifera e $V$. rotundifolia são suscetíveis à doença (Sonego et al., 2005). A ferrugem foi constatada pela primeira vez em uva fina 'Itália' ( $V$. vinifera), no entanto, em condições de campo, tem-se verificado que algumas cultivares copa, como: Niágara, Isabel, Rúbea, Vênus e os porta-enxertos 420A e Kober 5BB, são mais afetadas pela doença do que as cultivares do grupo Itália e alguns porta-enxertos, como: IAC766 e IAC513 (Angelotti, 2006). Diferenças entre os genótipos cultivados de videira quanto a reação à ferrugem são esperadas, uma vez que boa parte dos genótipos resultaram de cruzamentos interespecíficos que ocorreram, eventualmente, com genótipos resistentes.

A resistência genética parcial, também chamada de resistência quantitativa ou incompleta, proporciona baixas taxas de desenvolvimento das doenças no campo. Com relação às ferrugens, esse tipo de resistência resulta da combinação de diversos componentes, como: freqüência de infecção, tamanho de pústulas, quantidade de esporos produzidos por pústula e período latente (Parlevliet, 1985).

A resistência genética é estratégia importante para o controle de doenças, e é altamente desejável do ponto de vista ambiental e econômico. Assim, a identificação a caracterização de genótipos, com maiores graus de resistência ou imunidade à ferrugem, são importantes para programas de melhoramento genético que visam o desenvolvimento de novas cultivares de videira.

A densidade do inóculo pode interferir na severidade das ferrugens (Melching, 1981; Pei et al., 2002; Gilles \& Kennedy, 2003); assim, o entendimento da relação entre densidade de inóculo e a intensidade da doença é importante em estudos de caracterização de resistência às ferrugens. Pelos mesmos motivos, deve ser conhecida a influência da idade da folha na severidade. Em campo, raramente tem sido observados sintomas de ferrugem-da-videira em folhas jovens. Naruzawa et al. (2006), por meio de teste de patogenicidade, realizado em folhas jovens e maduras de videira, em campo, verificaram a ausência de sintomas e sinais da doença em folhas jovens. Contudo, Leu \& Wu (1983) verificaram que, em folhas jovens infectadas com Phakopsora ampelopsidis (atualmente designada P. euvitis), as pústulas se desenvolveram.

O objetivo deste trabalho foi avaliar o grau de resistência à ferrugem, em genótipos de videira, e a influência da idade da folha e da concentração do inóculo na eficiência da infecção por P. euvitis.

\section{Material e Métodos}

As avaliações foram realizadas de dezembro/2005 a março/2006, no Laboratório de Fitopatologia da Universidade Estadual de Maringá. As mudas de videira utilizadas nos ensaios foram produzidas em vasos com capacidade de $2.000 \mathrm{~cm}^{3}$ de substrato, por meio de propagação de estacas com cinco gemas. Foi aplicada calcianamida $5 \%$ às gemas para quebra de dormência e obtenção de uniformidade na brotação.

A multiplicação dos urediniósporos, utilizados como inóculo nos ensaios, foi realizada em folhas de 'Niágara Rosada', em câmara de crescimento. Mudas com quatro a seis folhas foram infectadas por meio de pulverização, com suspensão de urediniósporos à concentração de $10^{5}$ esporos por $\mathrm{mL}$. Após a contaminação, as mudas foram submetidas à temperatura de $23-25^{\circ} \mathrm{C}$, com 24 horas de molhamento foliar, em ausência de luz. Posteriormente, as plantas foram mantidas em câmara de crescimento a $23-25^{\circ} \mathrm{C}$ e fotoperíodo de 12 horas. Os urediniósporos foram coletados dez dias após a infecção das plantas.

Para a determinação da influência da idade das folhas na colonização pelo fungo, foi conduzido ensaio em câmara de crescimento, com delineamento inteiramente ao acaso, e cinco repetições. As parcelas experimentais foram constituídas por vasos, com uma muda de 'Niágara Rosada', com quatro a seis folhas. A pulverização foi feita em folhas com 5,10 , 20, 30 e 60 dias de idade, por meio de suspensão de urediniósporos a $10^{5}$ esporos por $\mathrm{mL}$, em solução de Tween-20 a $0,01 \%$. A idade da folha foi contada a partir do estádio das primeiras folhas separadas - 
estádio fenológico 07, da escala de Eichhorn e Lorenz, descrita por Pratt (1988). Após a inoculação, seguiuse o período de incubação em câmara de crescimento, da forma descrita anteriormente. Para quantificar a doença, foi avaliado o número de pústulas por $\mathrm{cm}^{2}$, em quatro regiões do limbo foliar, de 6 a 10 dias após a inoculação. A quantificação foi feita com lupa de aumento de 20 vezes, acoplada a uma câmera fotográfica digital. Os dados foram transferidos para um computador para a contagem das pústulas.

Para se determinar a influência da concentração do inóculo na colonização, foi conduzido ensaio com delineamento inteiramente ao acaso e cinco repetições, em câmara de crescimento. As parcelas experimentais foram constituídas por vasos com uma muda de 'Niágara Rosada' com quatro a seis folhas. As mudas foram infectadas por meio de pulverização, com suspensões de urediniósporos a $10^{3}, 10^{4}, 10^{5}, 10^{6}$ e $10^{7}$ esporos por $\mathrm{mL}$. Após infecção, as mudas foram submetidas aos mesmos procedimentos do experimento anterior. Para quantificar a doença, foi avaliado o número de pústulas por $\mathrm{cm}^{2} \mathrm{em}$ quatro regiões do limbo foliar.

A análise da resistência genética à ferrugem foi realizada em 15 genótipos comerciais de videira, inclusive porta-enxertos e copas (Tabela 1), em ensaio com delineamento de blocos ao acaso, com cinco repetições. As repetições foram constituídas por vasos com uma planta com quatro a seis folhas. As mudas foram pulverizadas com uma suspensão de urediniósporos a $10^{5}$ esporos por $\mathrm{mL}$, em solução de Tween-20 a 0,01\%. Após a inoculação dos esporos, as mudas foram mantidas em câmara de crescimento, conforme descrito anteriormente. A severidade da doença foi quantificada por meio de escala diagramática para a avaliação da ferrugem-da-videira, elaborada por Angelotti (2006).

Foram avaliados os componentes de resistência dos genótipos à ferrugem. A eficiência de infecção foi avaliada por meio da quantificação do número de pústulas por $\mathrm{cm}^{2}$, em quatro regiões distintas do limbo foliar, em três folhas por repetição, 6 a 10 dias após a inoculação. A avaliação foi realizada com lupa de aumento de 20 vezes, acoplada a uma câmera digital e, em seguida, as imagens foram avaliadas em computador. $\mathrm{Na}$ determinação do comprimento de pústulas, o diâmetro de 20 delas foi medido em cada repetição, 10 dias após a inoculação. Para a obtenção do número de esporos produzidos por pústula, foram recortados quatro segmentos com $1 \mathrm{~cm}^{2}$ de folhas que continham soros urediniais, dez dias após a inoculação. Sob microscópio estereoscópico, quantificou-se o número de pústulas de cada segmento, que foram transferidos para tubos Eppendorf com $1 \mathrm{~mL}$ de água esterilizada e $1 \mu \mathrm{L}$ de Tween-20. Os esporos foram coletados por centrifugação (5.000 g por $1 \mathrm{~min}$ ). Estimou-se a concentração de esporos na suspensão em Câmara de Neubauer, tendo-se determinado, em seguida, o número de esporos por pústula, em cada segmento. $\mathrm{O}$ período latente foi determinado pela marcação de duas folhas por planta e pela quantificação diária do número de pústulas, a partir do aparecimento das primeiras pústulas esporulantes até a estabilização do número de pústulas formadas. Considerou-se, como período latente, o tempo decorrido, em dias, desde a infecção até o aparecimento de $50 \%$ de pústulas esporulantes.

A análise de variância multivariada (MANOVA) foi aplicada aos dados dos componentes de resistência. Os testes de hipótese de Wilks, traço de Pillai, traço de Hotelling-Lawley e maior raiz de Roy foram aplicados à MANOVA, para avaliar a nulidade dos vetores. A abordagem multivariada foi justificada porque os coeficientes de correlação observados entre as matrizes de erros dos componentes foram significativos, o que mostra associação entre as variáveis-resposta. Em seguida, foi aplicada a análise canônica aos componentes, com obtenção de quatro variáveis

Tabela 1. Genótipos de Vitis spp., testados quanto à resistência a Phakopsora euvitis, e suas origens.

\begin{tabular}{|c|c|c|}
\hline Genótipos & Características & Origem \\
\hline Bordô & Copa & Vitis labrusca \\
\hline Clara & Copa & $\begin{array}{l}\text { CNPUV 154-147 x Centennial } \\
\text { seedless }\end{array}$ \\
\hline Concord & Copa & V. labrusca \\
\hline IAC313 & Porta-enxerto & Golia $\mathrm{x} V$. cinerea \\
\hline $420-\mathrm{A}$ & Porta-enxerto & $V$. berlandieri $\mathrm{x} V$. riparia \\
\hline IAC572 & Porta-enxerto & V. tiliifolia $\mathrm{x}$ 101-14 Mgt \\
\hline IAC766 & Porta-enxerto & $\begin{array}{l}\text { V. tiliifolia } \times 106-8 \mathrm{Mgt} \\
{[V . \text { riparia } \times(V . \text { rupestris } \mathrm{x}} \\
V . \text { cordifolia })] \times \text { V. tiliifolia }\end{array}$ \\
\hline Isabel & Copa & $V$. labrusca $\times$ V. vinifera \\
\hline Itália & Copa & Bicane x Moscatel de Hamburgo \\
\hline Kober 5BB & Porta-enxerto & $V$. berlandieri $\mathrm{x} V$. riparia \\
\hline Niágara & Copa & $\begin{array}{l}\text { Concord ( } V \text {. labrusca ) x Cassady } \\
\text { (V. labrusca } \times \text { V vinifera }\end{array}$ \\
\hline Rúbea & Copa & Niágara x Bordô \\
\hline Rupestris & Porta-enxerto & V. rupestris \\
\hline Traviú & Porta-enxerto & $\begin{array}{l}\text { Vitis riparia } \mathrm{x} \text { (Vitis rupestris } \mathrm{x} \\
\text { Vitis cordifolia) }\end{array}$ \\
\hline Vênus & Copa & Alden x NY46000 \\
\hline
\end{tabular}


canônicas e da matriz de dissimilaridade genética dos genótipos, baseada na distância generalizada de Mahalanobis e estimada a partir dos vetores multidimensionais de médias. A análise de agrupamento foi realizada para se discriminarem os genótipos quanto à resistência à ferrugem. $\mathrm{O}$ método de agrupamento empregado foi o de otimização de Tocher modificado (Vasconcelos et al., 2007). As análises estatísticas foram realizadas por meio do programa GENES (Cruz, 1998) e do módulo STAT do SAS (SAS Institute, 2004).

\section{Resultados e Discussão}

A infecção por P. euvitis ocorreu em folhas de 'Niágara Rosada' com idade de 5 a 60 dias do início da brotação dos ramos, mas só apresentou níveis crescentes em folhas de 5 a 20 dias de idade (Figura 1 A). O grau de infecção não variou significativamente entre folhas jovens e maduras, com idades superiores a 20 dias. As idades de 20 a 60 dias correspondem aos estádios 12 (5-6 folhas separadas) a 29 (frutos pequenos; "chumbinho") da escala de Eichhorn e Lorenz. Leu \& Wu (1983) também verificaram que folhas jovens de videira, infectadas por $P$. euvitis, desenvolveram pústulas. Segundo Leu (1988), a infecção da ferrugemda-videira ocorre por meio dos estômatos, e isto pode explicar a maior quantidade de pústulas na face inferior
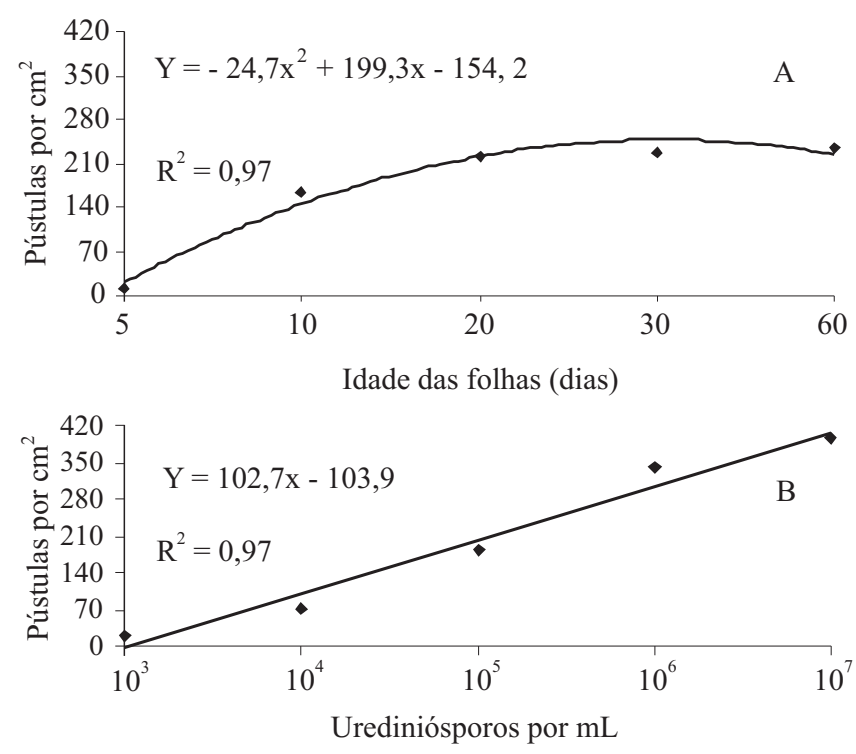

Figura 1. Colonização de Phakopsora euvitis em folhas de videira 'Niágara Rosada', após a inoculação em folhas de diferentes idades (A) e após a inoculação com diferentes concentrações de urediniósporos (B). das folhas e, também, os menores graus de infecção em folhas muito jovens. Naruzawa et al. (2006), por meio de teste de patogenicidade realizado em folhas jovens e maduras de videira, em campo, verificaram a ausência de sintomas e sinais da doença em folhas jovens. Isto pode ser explicado pelo aparecimento tardio da ferrugem, durante o ciclo da cultura, geralmente da fase de frutificação em diante (Tessmann \& Vida, 2005), o que possivelmente ocorre em razão da maior presença de inóculo nessa fase que, ademais, normalmente coincide com a ocorrência de condições climáticas favoráveis.

O grau de infecção aumentou linearmente com o aumento da concentração do inóculo na suspensão (Figura 1 B). Observou-se que, para o fungo P. euvitis, os urediniósporos são estimulados a germinar quando ocorrem em altas densidades na superficie das folhas, ao contrário do que ocorre com o fungo Puccinia polysora, em que o aumento da densidade de esporos inibe a germinação dos urediniósporos em folhas de milho (Melching, 1981). Constata-se que a densidade do inóculo pode ter interferido diretamente na germinação dos esporos e aumentado a eficiência de infecção, em altas concentrações. A severidade da ferrugem-da-videira aumentou em razão da concentração de inóculo, o que ressalta a importância do controle dos urediniósporos nas fontes de inóculo, principalmente nas regiões onde ocorrem duas safras, pois favorecem a presença do inóculo durante todo o ano.

Em campo, verificou-se que a quantidade máxima de infecção nas folhas de genótipos susceptíveis correspondeu à severidade proporcionada pelo emprego de concentrações de inóculo com $10^{4}$ a $10^{5}$ esporos por $\mathrm{mL}$, de acordo com a escala diagramática de Angelotti (2006).

Os componentes de resistência, com exceção do período latente, apresentaram grande variação quantitativa entre os genótipos (Tabela 2). Empregou-se a abordagem multivariada porque, pelo teste de Mauchly, rejeitou-se, a $1 \%$ de probabilidade, a condição de esfericidade para as matrizes de variância, entre os pares de intensidade de doenças; além disso os coeficientes de correlação linear de Pearson observados entre os componentes foram significativos, o que demonstra a associação (Tabela 3). A nulidade dos vetores de tratamentos mostraram-se significativos $(\mathrm{p}<0.001)$, o que indica que um ou mais genótipos diferem entre si quanto à resistência genética à ferrugem.

As duas primeiras variáveis canônicas explicaram 61 e 32,8\% da variação, respectivamente, com o percentual acumulado de 93,8\%. A distância generalizada de 
Mahalanobis discriminou cinco grupos de genótipos, quanto à resistência à ferrugem (Tabela 2), entre os quais merece destaque o grupo I, com as cultivares porta-enxertos IAC313, IAC572 e IAC766. Essas cultivares apresentam características de resistência bem distintas dos demais grupos: nelas a eficiência da infecção é mais baixa, apresentam pústulas menores, menor produção de urediniósporos por pústula e período latente de oito dias. Com relação ao número de pústulas por $\mathrm{cm}^{2}$, as cultivares do grupo V, Niágara e Rúbea, apresentaram os níveis mais elevados de infecção e o maior número de urediniósporos por pústula. A cultivar Itália, do grupo II, apresentou o menor número de pústulas por $\mathrm{cm}^{2}$ e menor número de urediniósporos por pústula entre as variedades copa. Os genótipos IAC 313, IAC572, IAC766, 420-A, Kober 5BB e Rupestris apresentaram necrose do tecido ("flecks") ao redor das pústulas, o que indica a ocorrência de reação de hipersensibilidade do hospedeiro (Figura 2).

Nos genótipos de videira, observou-se maior variação quanto à eficiência de infecção, tamanho de pústulas e número de urediniósporos produzidos por pústula, e variação menor em relação ao período latente. A importância relativa dos componentes de resistência pode variar de acordo com o patossistema estudado, como foi demonstrado para ferrugem-dafolha do trigo (Puccinia triticina Erickss.) (Parlevliet, 1985), ferrugem-da-folha da aveia (P. coronata f.sp. avenae Fraser \& Led.) (Chaves et al., 2004), e ferrugem asiática da soja (Phakopsora pachyrhizi) (Bonde et al., 2006; Azevedo et al., 2007).

A resistência quantitativa ou parcial atua por meio da redução da taxa de infecção, diminuição da produção de esporos, redução do tamanho das pústulas e aumento do período latente (Parlevliet, 1985). A variabilidade existente no número de pústulas, tamanho das pústulas e número de esporos produzidos por pústula, entre os genótipos de videira testados, mostrou grande variação quantitativa nesses caracteres, evidência da ocorrência de resistência parcial nos genótipos testados. A ocorrência de necrose ao redor das pústulas, em razão da reação de hipersensibilidade, evidencia o envolvimento de genes maiores de resistência (Bonde et al., 2006).

Tabela 2. Variáveis epidemiológicas apresentadas pelos genótipos de videira infectados por ferrugem (Phakopsora euvitis) ${ }^{(1)}$.

\begin{tabular}{|c|c|c|c|c|c|}
\hline Genótipo & $\begin{array}{c}\text { Número de } \\
\text { pústulas por } \mathrm{cm}^{2}\end{array}$ & $\begin{array}{l}\text { Diâmetro de } \\
\text { pústulas ( } \mu \mathrm{m})\end{array}$ & $\begin{array}{l}\text { Número de urediniósporos } \\
\text { por pústula }\end{array}$ & $\begin{array}{c}\text { Período } \\
\text { latente (dias) }\end{array}$ & Grupo $^{(2)}$ \\
\hline IAC766 & $25,0 \pm 17,1$ & $11,3 \pm 2,6$ & $1.793 \pm 625$ & $8,0 \pm 0,0$ & I \\
\hline IAC572 & $42,3 \pm 5,9$ & $13,4 \pm 2,1$ & $3.311 \pm 1.326$ & $8,0 \pm 0,0$ & I \\
\hline IAC 313 & $46,9 \pm 18,6$ & $11,3 \pm 2,3$ & $2.211 \pm 813$ & $8,0 \pm 0,0$ & I \\
\hline Traviú & $50,9 \pm 19,7$ & $24,6 \pm 3,2$ & $5.445 \pm 1.201$ & $7,0 \pm 0,0$ & II \\
\hline Rupestris & $61,7 \pm 19,5$ & $17,2 \pm 2,5$ & $4.421 \pm 718$ & $7,0 \pm 0,0$ & II \\
\hline Itália & $75,9 \pm 32,8$ & $25,1 \pm 2,1$ & $4.813 \pm 1.072$ & $7,0 \pm 0,0$ & II \\
\hline $420-\mathrm{A}$ & $76,7 \pm 18,1$ & $17,0 \pm 2,3$ & $4.020 \pm 1.437$ & $7,0 \pm 0,0$ & II \\
\hline $5 \mathrm{BB}$ & $95,6 \pm 31,8$ & $24,2 \pm 2,1$ & $5.241 \pm 1.571$ & $7,0 \pm 0,0$ & II \\
\hline Isabel & $66,5 \pm 14,0$ & $21,7 \pm 3,1$ & $9.086 \pm 4.357$ & $8,0 \pm 0,0$ & III \\
\hline Concord & $91,1 \pm 36,4$ & $27,2 \pm 4,3$ & $7.375 \pm 3.654$ & $8,0 \pm 0,0$ & III \\
\hline Vênus & $103,3 \pm 36,4$ & $20,6 \pm 1,4$ & $8.151 \pm 2.403$ & $8,0 \pm 0,0$ & III \\
\hline Clara & $49,3 \pm 22,0$ & $27,9 \pm 8,0$ & $11.508 \pm 7.326$ & $7,8 \pm 0,4$ & IV \\
\hline Rúbea & $106,8 \pm 30,8$ & $29,1 \pm 4,2$ & $15.058 \pm 8.324$ & $7,0 \pm 0,0$ & V \\
\hline Bordô & $138,6 \pm 43,7$ & $26,4 \pm 1,2$ & $6.074 \pm 2.551$ & $7,0 \pm 0,0$ & V \\
\hline Niágara Rosada & $159,6 \pm 41,7$ & $34,6 \pm 2,6$ & $19.014 \pm 6.288$ & $7,0 \pm 0,0$ & V \\
\hline
\end{tabular}

${ }^{(1)}$ Médias \pm desvio-padrão. ${ }^{(2)}$ Agrupamento dos genótipos pelo uso da distância generalizada $\mathrm{D}^{2}$ de Mahalanobis e pelo método de otimização de Tocher modificado (Vasconcelos, 2007).

Tabela 3. Coeficientes de correlação de Pearson entre os componentes de resistência.

\begin{tabular}{lccc}
\hline Variável & Número de pústulas por $\mathrm{cm}^{2}$ & Número de esporos por pústula & Diâmetro de pústulas \\
\hline Número de esporos por pústula & $0,41^{* *}$ & - & - \\
Diâmetro de pústulas & $0,41^{* *}$ & $0,51^{* *}$ & - \\
Período latente & $-0,47^{* *}$ & $-0,13 \mathrm{~ns}$ & $-0,33^{* *}$ \\
\hline
\end{tabular}

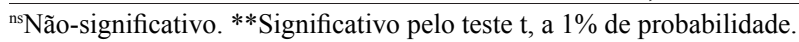



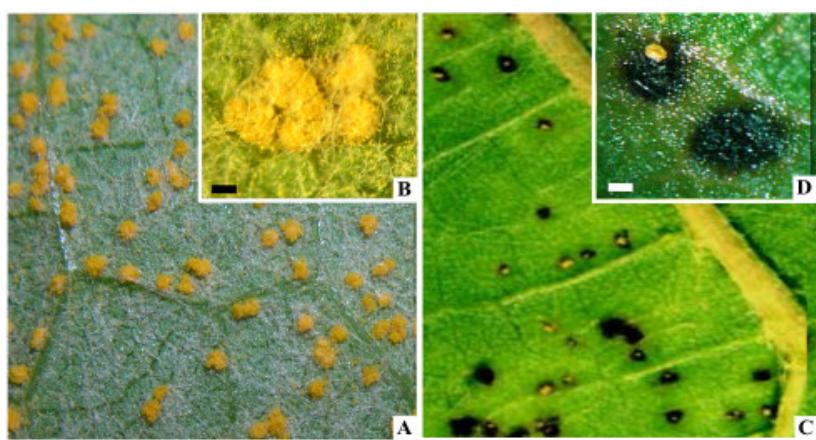

Figura 2. Soros urediniais de Phakopsora euvitis na videira. A e B: formação de pústulas típicas, esporulantes em folhas de 'Niágara'; C e D: pústulas com necrose do tecido circundante e esporulação reduzida no porta-enxerto IAC572 (barra $=10 \mu \mathrm{m})$.

\section{Conclusões}

1. Genótipos de videira apresentam diferenças no grau de resistência à ferrugem; os genótipos mais resistentes são as cultivares porta-enxertos IAC313, IAC572 e IAC766, em que a eficiência da infecção é baixa.

2. O grau de infecção aumenta com o aumento na concentração do inóculo.

3. A ferrugem coloniza, indiscriminadamente, folhas jovens e folhas maduras de videira.

\section{Referências}

ANGELOTTI, F. Epidemiologia da ferrugem (Phakopsora euvitis) da videira (Vitis spp.). 2006. 66p. Tese (Doutorado) Universidade Estadual de Maringá, Maringá.

AZEVEDO, L.A.S. de; JULIATTI, F.C.; BARRETO, M. Resistência de genótipos de soja à Phakopsora pachyrhizi. Summa Phytopathologica, v.33, p.252-257, 2007.

BONDE, M.R.; NESTER, S.E.; AUSTIN, C.N.; STONE, C.L.; FREDERICK, R.D.; HARTMAN, G.L.; MILES, M.R. Evaluation of virulence of Phakopsora pachyrhizi and P. meibomiae isolates. Plant Disease, v.90, p.708-716, 2006.

CHAVES, M.S.; MARTINELLI, J.A.; FEDERIZZI, L.C. Resistência quantitativa à ferrugem-da-folha em genótipos de aveia-branca: II - avaliação de componentes de resistência. Fitopatologia Brasileira, v.29, p.43-51, 2004.

CRUZ C.D. Programa GENES: aplicativo computacional em estatística aplicada à genética (GENES - Software for Experimental Statistics in Genetics). Genetics and Molecular Biology, v.21, p.135-138, 1998.
GILLES, T.; KENNEDY, R. Effects of an interaction between inoculum density and temperature on germination of Puccinia allii urediniospores and leek rust progress. Phytopathology, v.93, p.413-420, 2003.

LEU, L.S. Rust. In: PEARSON, R.C.; GOHEEN, A.C. (Ed.). Compendium of grape diseases. Minnesota: APS, 1988. p.28-30.

LEU, L.S.; WU, H.G. Uredospore germination, infection and colonization of grape rust fungus, Phakopsora ampelopsidis. Plant Protection Bulletin, v.25, p.167-175, 1983.

MELCHING, J.S. The effect of inoculum density on uredospore germination and infection of corn by Puccinia polysora, the cause of southern corn rust. Phytopathology, v.71, p.769, 1981.

NARUZAWA, E.S.; CELOTO, M.I.B.; PAPA, M.F.S.; TOMQUELSKI, G.V.; BOLIANI, A.C. Estudos epidemiológicos e controle químico de Phakopsora euvitis. Fitopatologia Brasileira, v.31, p.41-45, 2006.

ONO, Y. Taxonomy of the Phakopsora ampelopsidis species complex on vitaceous hosts in Asia including a new species, P. euvitis. Mycologia, v.92, p.154-173, 2000.

PARLEVLIET, J.E. Resistance of the nonrace-specific type. In: BUSHNELL, W.R.; ROELFS, A.P. (Ed.). The cereal rusts: diseases, distribution, epidemiology and control. New York: Academic Press, 1985. p.501-525.

PEI, M.H.; RUIZ, C.; HUNTER, T.; ARNOLD, G.M.; BAYON, C. Quantitative relationships between inoculum of Melampsora laricis-epitea and corresponding disease on Salix. Plant Pathology, v.51, p.443-453, 2002.

PRATT, C. Grapevine structure and growth stages. In: PEARSON, R.C.; GOHEEN, A.C. (Ed.). Compendium of grape diseases. Minnesota: APS, 1988. p.3-7.

SAS INSTITUTE. SAS versão $\mathbf{8 . 2}$ para Windows. Cary: SAS Institute, 2004.

SONEGO, O.R.; GARRIDO, L. da R.; GAVA, R. Ferrugem-davideira no Brasil. Bento Gonçalves: Embrapa Uva e Vinho, 2005. 4p. (Embrapa Uva e Vinho. Comunicado Técnico, 62).

TESSMANN, D.J.; DIANESE, J.C.; GENTA, W.; VIDA, J.B.; MIO, L.L.M. Grape rust caused by Phakopsora euvitis, a new disease for Brazil. Fitopatologia Brasileira, v.29, p.338, 2004.

TESSMANN, D.J.; VIDA, J.B. A ferrugem-da-videira no Brasil. In: CONGRESSO BRASILEIRO DE FITOPATOLOGIA, 38., 2005, Brasília. Anais. Brasília: Sociedade Brasileira de Fitopatologia, 2005. p.220-222.

VASCONCELOS, E.S. de; CRUZ, C.D.; BHERING, L.L.; RESENDE JÚNIOR, M.F. Método alternativo para análise de agrupamento. Pesquisa Agropecuária Brasileira, v.42, p.14211428, 2007.

WEINERT, M.P.; SHIVAS, R.G.; PITKETHLEY, R.N.; DALY, A.M. First record of grapevine leaf rust in the Northern territory, Australia. Australasian Plant Pathology, v.32, p.117-118, 2003.

Recebido em 22 de junho de 2008 e aprovado em 26 de agosto de 2008 